\title{
Curriculum Mapping in Engineering Education: Linking ATtributes, OUTCOMES AND AsSessments Curriculum Mapping in Engineering Education: Linking Attributes, Outcomes and Assessments
}

\author{
Darlene Spracklin-Reid and Andy Fisher \\ Memorial University \\ darlenesr@mun.ca, adfisher@mun.ca
}

\begin{abstract}
In 2010, the Canadian Engineering Accreditation Board (CEAB) began reviewing programs for progress toward assessment of graduate attributes. This represented a significant change from traditional inputs-based to outcomes-based accreditation. The Faculty of Engineering and Applied Science at Memorial University responded by linking course-based learning outcomes to graduate attributes and assessments in a live, online curriculum map. This paper provides an overview of the curriculum mapping approach taken by the Faculty of Engineering and Applied Science at Memorial University.
\end{abstract}

Keywords: Curriculum Mapping, Engineering Education, Graduate Attributes

\section{INTRODUCTION}

The development of comprehensive learning outcomes for all core courses in the engineering program is the foundation for Memorial University's approach to the Canadian Engineering Accreditation Board's (CEAB) outputs-based accreditation [1]. The graduate attributes as defined by the CEAB are our program outcomes; the assessment of these program outcomes is achieved through the assessment of course-based learning outcomes that contribute to attribute development.

Graduate attributes are a composite of the knowledge, skills and attitudes that are developed and demonstrated throughout the engineering program [2]. Measureable learning outcomes allow for the assessment of graduate attributes as they develop and they are an important component of the quality assurance and continual improvement process. Using a complete and comprehensive set of learning outcomes, deficiencies in acquiring graduate attributes can be identified and problems can be addressed in a timely way. A set of comprehensive learning outcomes are the foundation of curriculum maps that provide the detail required to identify areas for improvement in the program.
Curriculum mapping is effective in operationalizing outcome-based education and they play an important role in determining whether the curriculum meets specified standards and is aligned with expected learning outcomes [3].

\section{CURRICULUM MAPPING SOFTWARE}

Faculty, staff and students work collaboratively to develop learning outcomes, assessment techniques and curriculum maps. In an effort to draw useful information from our data, we are working collaboratively with a software developer to build a customizable curriculummapping program. Features include the ability to identify where each graduate attribute is being taught and how it is being assessed.

The database, and the curriculum map it informs, is searchable by graduate attribute. A search for a specific graduate attribute tells the user the courses in which that attribute is being developed, the specific learning outcomes or indicators associated with that graduate attribute, and how those outcomes, and therefore the graduate attribute, are being measured.

This bottom-up approach ensures that a comprehensive curriculum map is created, and we are able to track graduate attributes as they develop, and measure that development as it occurs. It allows for quality assurance of the program, and facilitates continuous improvement.

\section{References}

[1] Engineers Canada, Canadian Engineering Accreditation Board, "2010 Accreditation Criteria and Procedures", www.engineerscanada.ca, 2010.

[2] Simon C. Barrie, "A research-based approach to generic graduate attributes policy." Higher Education Research \& Development, 31:1, 79-92, 2012.

[3] Harden, R. M. (2001). AMEE Guide No. 21: Curriculum mapping: a tool for transparent and authentic teaching and learning. Medical Teacher, 23(2), 123-137. 